\title{
A Triple-band Suspended Microstrip Antenna with Symmetrical U- Slots for WLAN/WiMax Applications
}

\author{
Seshadri Binaya Behera ${ }^{1}$, Debaprasad Barad ${ }^{2}$, and Subhrakanta Behera ${ }^{3}$ \\ ${ }^{123}$ School of Electronics Engineering, KIIT University, Bhubaneswar-24, India. \\ *corresponding author, E-mail: subhrajsp@gmail.com
}

\begin{abstract}
In this study, a triple-band suspended microstrip antenna with symmetrical U-slots is proposed for modern wireless communication systems. The antenna is specifically designed to acquire application in WLAN and WiMAX communication. Symmetrical U-slots in the radiator patch increase the number of resonances and improve the gain response. An appropriate air height was maintained between the ground plane and the radiator patch layer for improving bandwidth operation. The impedance characteristics of the antenna are enhanced using probe feeding techniques. The proposed compact antenna is designed on a single dielectric substrate of $(30 \times 25 \times 1.56) \mathrm{mm}^{3}$. Parametric analysis of the proposed structure has been realized using IE3D software. This prototype exhibits maximum impedance bandwidth of $750 \mathrm{MHz}$ and gain response of $7.28 \mathrm{dBi}$. The performance of the structure at three resonating bands i.e., at $3.3 \mathrm{GHz}$, $3.78 \mathrm{GHz}$ and $5.3 \mathrm{GHz}$ facilitate it to be applicable for WLAN/WiMAX systems.
\end{abstract}

Keywords: High Gain; Microstrip Antenna; Multiband; U-Slots; Suspended antenna patch; WLAN/WiMAX

\section{Introduction}

Microstrip antenna offers extensive applications in wireless communication systems due to its low profile, light weight and ease of integration with the RF/Microwave systems [1]. Lately, many researchers have drawn their attention towards the design of compact microstrip antennas which can operate over a wide range of frequencies. In some cases it is desirable to incorporate a single antenna which can support two or more applications simultaneously. These types of antennas are referred as "Multiband" antennas; particularly, multi-frequency antenna for multi-standard communication.

In 1978, G.G. Sanford [2] introduced the concept of using a microstrip antenna for achieving multiple resonances. Later, many authors [3-5] worked on the same concept and developed several multiband antenna models. S. Long and M. Walton [3], investigated a stacked circulardisc printed-circuit antenna for dual-frequency behavior. Single-feed microstrip antenna using multi-element radiator patch with a common input point was invented by C. kaloi [4] in 1981. A single-element microstrip antenna with shorting pins was investigated for dual-frequency operation [5]. However, narrow impedance bandwidth is a major disadvantage of using a microstrip antenna. Various techniques can be found in literature to overcome this problem. In [6], the authors used CPW feeding technique to enhance the impedance bandwidth of patch antenna. X.L. Sun, et al. [7] proposed a patch antenna structure with compact radiator patches which covered all the bands of WLAN i.e., 2.4/5.2/5.8 GHz with better impedance bandwidth characteristics. Use of meander lines[8] and PIFA related miniaturized antennas [9] are also found in literature for the same purpose. However, introduction of Uslots on patch antenna is a very popular method to achieve wideband characteristics. In 1995, T.Hyunh [10] first introduced U-slots on microstrip antenna and increased the impedance bandwidth up to $10-30 \%$. Later, several research works have been carried out using U-slots to obtain wideband characteristics [11-13]. Also, these U-slots create discontinuities in the current flow path, thus creating multiple paths for current flow of the patch surface. This enables the microstrip antenna to show multiband behavior.

This work focuses on designing a compact patch antenna with simple structure which can operate in both WLAN (5150 MHz-5350 MHz) and WiMAX (3.2-3.8 GHz and 5.2-5.8 GHz) bands with good impedance bandwidth and good boresight gain. Some of the previously reported antenna structures in the literature are compared with the proposed antenna in Table 1.

In this paper, a triple-band microstrip antenna with symmetrical U-slot and two half U-slots is investigated. The multi-resonance characteristics are achieved by introducing U-slots at appropriate positions with respect to the feeding point, which enables the antenna to first resonate at $3.3 \mathrm{GHz}$ and later at $3.78 \mathrm{GHz}, 5.3 \mathrm{GHz}$. The antenna patch is placed above the ground plane by maintaining a suitable air height in between the two layers to enhance the antenna performance. The impedance characteristics of the antenna are enhanced using probe feeding techniques. The antenna yields a maximum impedance bandwidth of $750 \mathrm{MHz}$ with the maximum gain response of $7.28 \mathrm{dBi}$ by optimizing the air layer height and the dimension of U-slot. A parametric study of various factors of the proposed antenna structure is executed. The simulation results obtained were validated with experiment and both the results match well. As observed in Table 1, the proposed antenna exhibits better 
performance with compact size. However, the said antenna with these unique and better characteristics, as compared to the literature, is proposed for Wi-MAX / WLAN communication.

Table 1. Performance comparison of the proposed structure with other structures

\begin{tabular}{|c|c|c|c|c|}
\hline Ref. No. & Dime & $\begin{array}{l}\text { ension } \\
\mathrm{s}\end{array}$ & $\begin{array}{c}\text { Resonance } \\
\text { Frequencies } \\
(\mathrm{GHz})\end{array}$ & $\begin{array}{l}\text { Gain } \\
\text { (in dBi) }\end{array}$ \\
\hline$[14]$ & 80 & $\times 45$ & $\begin{array}{l}1.71,2.2,5.2, \\
5.7\end{array}$ & $\begin{array}{l}2.15, \quad 3.5, \\
2.9,3.75\end{array}$ \\
\hline$[15]$ & 80 & $\times 80$ & $2.45,3.5,5.5$ & $1.7,2,3.9$ \\
\hline$[16]$ & 50 & $\times 50$ & $2.44, .5,5.25,5.8$ & $\begin{array}{l}3.94, \quad 4.9, \\
5.4,4.8\end{array}$ \\
\hline$[17]$ & 100 & $\times 60$ & $2.5,3.5,5.5$ & $\begin{array}{l}3.75,3.56 \\
3.93\end{array}$ \\
\hline$[18]$ & 54 & $\times 30$ & $2.45,5.2,5.8$ & $\begin{array}{l}1.4, \quad 5.5, \\
8.9\end{array}$ \\
\hline [19] & 56 & $\times 44$ & $\begin{array}{l}1.57,2.45, \quad 3.5, \\
5.2\end{array}$ & $\begin{array}{l}3.55,3.93 \\
5.02,4.86\end{array}$ \\
\hline $\begin{array}{l}\text { Proposed } \\
\text { antenna }\end{array}$ & 30 & $\times 25$ & 3.3, 3.78,5.3 & $\begin{array}{l}7.18,6.05, \\
4.6\end{array}$ \\
\hline
\end{tabular}

\section{Design and Analysis of Antenna Structure}

The proposed antenna structure is implemented on a single dielectric substrate. A low cost FR4 substrate with a dielectric constant $\left(\varepsilon_{\mathrm{r}}\right) 4.4$, substrate height of $1.56 \mathrm{~mm}$, loss tangent $(\tan \delta)$ of 0.02 is considered in this study.

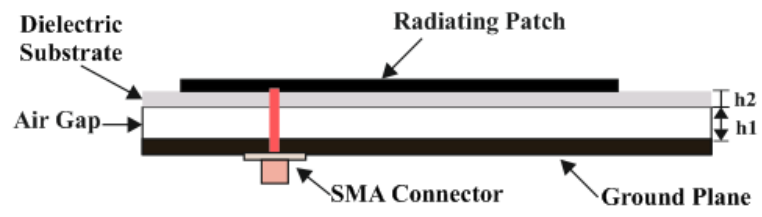

Figure 1. Side view of the proposed antenna

The cross-sectional view of the proposed structure is shown in Figure 1. In which, the antenna radiator patch is placed on the top layer with a suitable air height of $h_{1}$ from the ground plane. The height caused by the subsequent layer improves the operational bandwidth at specific resonant frequencies $\left(f_{r}\right)$. Below to this air layer a fully conductive copper plate is considered as ground plane. The feeding technique used here is coaxial probe feeding method. The advantage of using this technique is that, the feed point can be placed at any location on the patch as desired.

The geometry of the proposed microstrip antenna radiator is shown in figure 2 and the dimension details are given in Table 2. A microstrip layer of dimension $(30 \times 25) \mathrm{mm}^{2}$ is considered for the designing the antenna geometry. The performance of the antenna structure is optimized by adding U-slots onto it. The step-by-step approach is depicted in figure 2 .

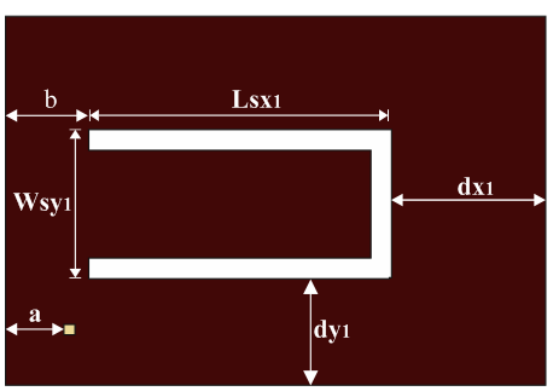

(a) Antenna 1

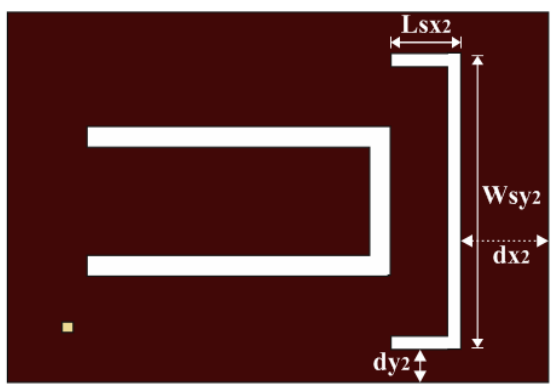

(b) Antenna 2

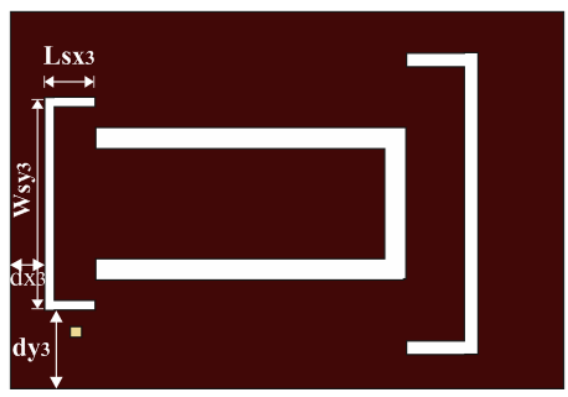

(c) Antenna 3

Figure 2. Iterative development of the proposed antenna.

The proposed structure is designed by implementing the basic design constraints available in literature [1]. However, the effective dielectric constant can be calculated with equation 1 as this antenna is a multi-dielectric structure; an air layer being one of them [20].

$\varepsilon_{\text {reff }}=\frac{\varepsilon_{r}\left(1+\left(h_{1} / h_{2}\right)\right)}{\left(1+\varepsilon_{r}\left(h_{1} / h_{2}\right)\right)}$

Where ;

$h_{1}=$ height of the air gap

$h_{2}=$ height of the dielectric substrate

$\varepsilon_{r}=$ dielectric constant of the substrate 
Also, the optimum value of the dimension of the first Uslot can be estimated by using equation 2-4 [21];

$$
\begin{aligned}
& f_{1}=\frac{c}{2\left(\left(w_{s y 1} / 2\right)+L+(3 / 2) \Delta l-(d x 1 / 2)\right) \sqrt{\varepsilon_{\text {reff }}}} \\
& f_{2}=\frac{c}{\left((W / 2)+L+(3 / 2) \Delta l-\left(w_{s y 1} / 4\right)+a-b-(d x 1 / 2)\right) \sqrt{\varepsilon_{\text {reff }}}} \\
& \Delta l=0.412 h \frac{\left(\varepsilon_{\text {eff }}+0.3\right)\left(\frac{W}{h}+0.26\right)}{\left(\epsilon_{\text {reff }}-0.258\right)\left(\frac{W}{h}+0.8\right)}
\end{aligned}
$$

Where $\mathrm{c}$ is the velocity of light and $\Delta l$ is the length due to fringing field.

Table 2 Optimized values of the Antenna parameter.

\begin{tabular}{ll}
\hline Parameters & Values \\
\hline Dielectric constant $(\mathrm{Cr})$ & 4.4 \\
Substrate height & $1.56 \mathrm{~mm}$ \\
Loss tangent $(\tan \delta)$ & 0.02 \\
$\mathrm{~L}$ & $30 \mathrm{~mm}$ \\
$\mathrm{~W}$ & $25 \mathrm{~mm}$ \\
$\mathrm{~L} 3$ & $10 \mathrm{~mm}$ \\
$\mathrm{~L}_{\mathrm{sx} 1}$ & $19.4 \mathrm{~mm}$ \\
$\mathrm{~W}_{\mathrm{sx} 1}$ & $11 \mathrm{~mm}$ \\
$\mathrm{~L}_{\mathrm{sx} 2}$ & $6.5 \mathrm{~mm}$ \\
$\mathrm{~W}_{\mathrm{sx} 2}$ & $18 \mathrm{~mm}$ \\
$\mathrm{~L}_{\mathrm{sx} 3}$ & $3 \mathrm{~mm}$ \\
$\mathrm{~W}_{\mathrm{sx} 3}$ & $15.5 \mathrm{~mm}$ \\
\hline
\end{tabular}

\subsection{Effect of $1^{\text {st }} U$-slot:}

The rectangular suspended patch of dimension $(30 \times$ 25) $\mathrm{mm}^{2}$ resonates at $4 \mathrm{GHz}$ and $5.5 \mathrm{GHz}$. As we know, the middle band of WiMAX system ranges from 3.2-3.8 $\mathrm{GHz}$, thus the first resonance needs to be shifted back to fall within the specified range. After adding the first U-slot at the appropriate position as depicted in Figure 2a, the resonant frequency shifts from $4 \mathrm{GHz}$ to $3.67 \mathrm{GHz}$ and from $5.5 \mathrm{GHz}$ to $5.39 \mathrm{GHz}$ and this structure exhibits gain response of $5 \mathrm{dBi}$ and $1.1 \mathrm{dBi}$ respectively.

\subsection{Effect of $2^{\text {nd }} \mathrm{U}$-slot:}

The second half U-slot on the patch is introduced at the back side of the first U-slot with a suitable distance, which was found after numerous full wave simulation analysis [Figure 2b]. This gives way to another path for current flow, which enables the antenna to operate over three bands simultaneously; at $3.34 \mathrm{GHz}$ with gain $6.2 \mathrm{dBi}$, at $3.8 \mathrm{GHz}$ with gain of $6.7 \mathrm{dBi}$ and at $5.3 \mathrm{GHz}$ at $1.5 \mathrm{dBi}$.

Here, determining the position of the second slot is based on current distribution of the previous structure, i.e. Antenna 1. Etching of this slot should be at that portion on the patch which shows minimum surface current distribution. Also, it is well known from the basic antenna theory [22] that, fringing effect at the edge is responsible for the radiation mechanism of a patch antenna. Introduction of the slots on the patch provides additional edges, which affects the effective fringing field of the antenna and improves the radiation behaviour of the antenna structure. Thus, the gain response of the structure is a combined effect of patch and the slots.

\subsection{Effect of $3^{\text {rd }} \mathbf{U}$-slot:}

The same principle discussed in the above section is followed up to add another half U-slot onto the patch which is placed on the opposite side of the second U-slot to enhance the gain of the antenna [Figure 2c]. The position of this slot is determined through IE3D optimization With the $3^{\text {rd }}$ slot dug on the patch surface, number of discontinuities in current flow path increases, which in turn improves the radiation characteristics at those portions of the patch which are liable for the corresponding resonant frequencies. Finally, the proposed antenna resonates at $3.3 \mathrm{GHz}, 3.78$ $\mathrm{GHz}$ and at $5.3 \mathrm{GHz}$ with gain $7.28 \mathrm{dBi}, 6.95 \mathrm{dBi}$ and 4.5 $\mathrm{dBi}$ respectively.

The surface current distribution of the designed antenna at each resonant frequency is demonstrated in Figure 3. Also the respective colour pallete is placed alongside it. On the antenna patch, existence of red colour indicated maximum flow of current in the corresponding portion. It is observed that, the density of current flow is maximum near the edge of different U-slots present on the radiator patch. In Figure 3 , the current density near the U-slots varies at each instance; which indicates, the edge excitation due to the corresponding slots contributes to the respective resonant frequency as demonstrated in Figure 3a, b, c.

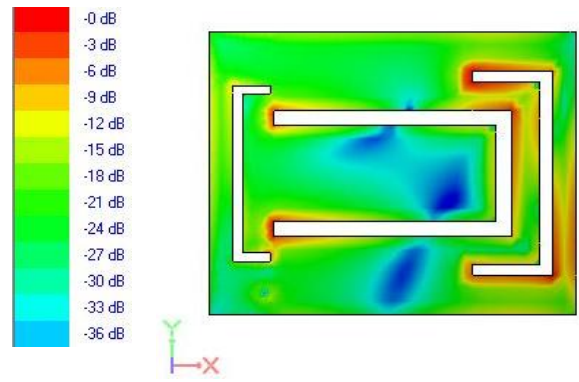

(a) $3.3 \mathrm{GHz}$

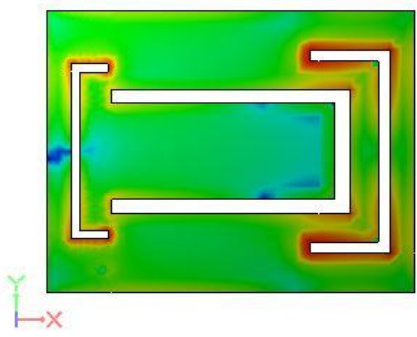

(b) $3.78 \mathrm{GHz}$

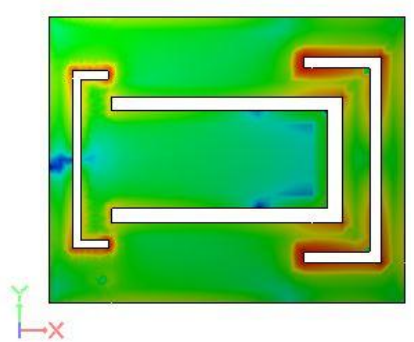

(c) $5.3 \mathrm{GHz}$
Figure 3 Surface current distributions at each resonant frequency.

\section{Parametric Study of the Proposed Structure}

As discussed, the proposed antenna is introduced with multiple parameters to boost the antenna performance. So 
the parametric analysis has been investigated to conclude best antenna characteristics. The detailed study by optimizing different parameters of the said structure is reported in below section.

\subsection{Effect of Air Height Variation}

In this study, the air layer is introduced deliberately to yield wideband response in desired resonating band. In addition to this the slot architecture improves the gain response of the designed microstrip antenna. This concept has been observed and validated through full wave simulation study as charted in Table 3.

Table 3. Parametric study by optimizing air height.

\begin{tabular}{ccc}
\hline $\begin{array}{c}\text { Air Height }\left(\mathrm{h}_{1}\right) \\
\text { in mm }\end{array}$ & $\begin{array}{c}\text { Return Loss in } \\
\mathrm{dB}\end{array}$ & Gain in dBi \\
\hline 3.38 & $11,14.3,14.6$ & $5.9,6.32,4.1$ \\
4.03 & $16.9,13.2,12.4$ & $6,6.34,4.1$ \\
4.23 & $18.5,14.8,13.9$ & $6.18,6.58,4.23$ \\
$\mathbf{4 . 4 3}$ & $\mathbf{2 0 . 2 , 1 7 . 9 , 1 7 . 7}$ & $\mathbf{7 . 2 8 , 6 . 9 5 , 4 . 5}$ \\
4.63 & $20.2,15.1,15.6$ & $7.2,6.95,4.56$ \\
4.83 & $21,13.5,14.1$ & $6.68,6.83,4.3$ \\
5.03 & $16.7,11.1,10.5$ & $6.7,6.73,4.4$ \\
\hline
\end{tabular}

The parametric study clearly indicates that, the change in air height has an impact on impedance matching and gain of the patch antenna. To maintain a trade-off between these two characteristics, the air height has been chosen as $4.43 \mathrm{~mm}$.

\subsection{Effect of Slot Dimension Variation}

An experimental analysis has been carried out by optimizing the length of the U-slot. The experimental result shows a negligible effect on gain response, but the return loss characteristics vary accordingly as depicted in Figure 4.

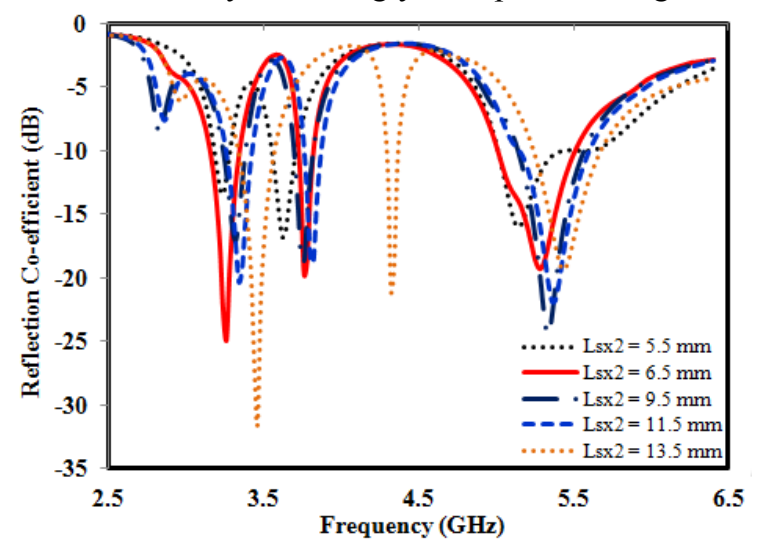

Figure 4 Return loss characteristics with different U-slots.

\subsection{Effect of Probe Feed Position}

The excitation angle mainly depends on the feed point position where the probe is connected. The angle of excitation changes the electrical property of the radiator patch which noticeably changes the characteristics of the designed antenna. The electric distribution on the designed radiator is changed due to change of feeding location. This concept has been validated through the simulation study as recorded in Table 4. Primarily for the reference purpose the center of the patch is assumed to be at $(0,0)$ on XY-plane. Later, relocation of the feeding point significantly affects the performance of the designed suspended antenna.

Table 4. A parametric study by relocating feed position.

\begin{tabular}{cccc}
\hline $\begin{array}{c}\text { Probe feed } \\
\text { position }\end{array}$ & $\begin{array}{c}\text { Resonant } \\
\text { Frequency } \\
\text { In GHz }\end{array}$ & $\begin{array}{c}\text { Return } \\
\text { Loss in dB }\end{array}$ & Gain in dBi \\
\hline$(0,0)$ & $2.9,3.7$ & $8.4,22.8$ & $2.51,5.19$ \\
$(0.5,-0.5)$ & $2.9,3.7$ & $10.3,19.7$ & $6.12,6.4$ \\
$(-0.5,0.5)$ & $2.9,3.7$ & $6.9,16.4$ & $5,5.9$ \\
$(0.5,0.5)$ & $2.9,3.7$ & $10.2,20$ & $6.25,6.42$ \\
$(1.5,0.5)$ & $2.97,3.76$ & $22,20.9$ & $5.05,6.16$ \\
$(5,-7)$ & $2.15,3.14$, & $13.4,21.6$, & $-1.95,4.98$, \\
& 3.78 & 25 & 6.98 \\
$(4.5,8.5)$ & $2.16,3.32$, & $20.6,23.9$, & $-3,7.2,6.67$ \\
& 3.76 & 23.6 & \\
$(3.5,7.5)$ & $2.16,3.35$, & $13.5,16.8$, & $-1.06,6.8$, \\
& 3.71 & 15.8 & 6.6 \\
$(\mathbf{- 1 0 . 5 , - 1 0 . 5 )}$ & $\mathbf{3 . 3 , 3 . 7 ,}$ & $\mathbf{2 0 . 2 , 1 7 . 9 ,}$ & $\mathbf{7 . 2 8 , 6 . 9 5 ,}$ \\
& $\mathbf{5 . 2 9}$ & $\mathbf{1 7 . 7}$ & $\mathbf{4 . 5}$ \\
\hline
\end{tabular}

\section{Results Discussion}

Proposed antenna design is simulated with Hyperlynx EM simulator IE3D software and the results obtained are discussed here in this section. Figure 5 shows the reflection co-efficient $\left(\mathrm{S}_{11}\right)$ comparison of the antenna geometry presented in figure 1. It has been observed that adding all the slots onto the radiator patch leads to achieve a good return loss $\left(\left|\mathrm{S}_{11}\right|\right)$. With the use of Antenna 1, dual-band operation can be performed while the use of Antenna 2 and Antenna 3 exhibits triple-band operation.

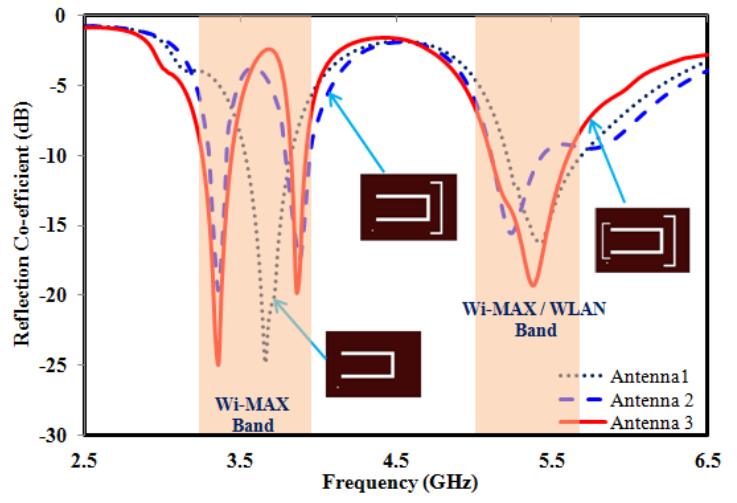

Figure 5 Return loss characteristics with different U-slots.

The proposed antenna resonates at three different frequencies, i.e. at $3.3 \mathrm{GHz}, 3.7 \mathrm{GHz}$ and $5.3 \mathrm{GHz}$. Here, the first two frequencies fall under the middle band of WiMAX communication systems, whereas the last resonance frequency can be used for both WiMAX and WLAN 
applications. The three resonant frequencies yield return losses of approximately $20.2 \mathrm{~dB}$ with an impedance bandwidth of $140 \mathrm{MHz}, 17.9 \mathrm{~dB}$ with an impedance bandwidth of $108 \mathrm{MHz}$ and $17.7 \mathrm{~dB}$ with impedance bandwidth $750 \mathrm{MHz}$.

The proposed microstrip antenna module was fabricated, in which the antenna geometry is designed on the top of the dielectric substrate. As discussed in the design section, the fully conductive ground plane is designed using a thin copper plate. The SMA connector is placed beneath the ground plane, wherein the feed line is extended and connected at the specified position. The radiator patch is suspended above the ground plane with suitable air height as discussed. Proper alignment of the said layers turns out best measurement results. The co-axial signal cable is connected to the antenna via SMA connector. The final fabricated prototype is shown in figure 6; figure 6(a) shows the top view and figure $6(\mathrm{~b})$ shows the cross section view of the fabricated module.

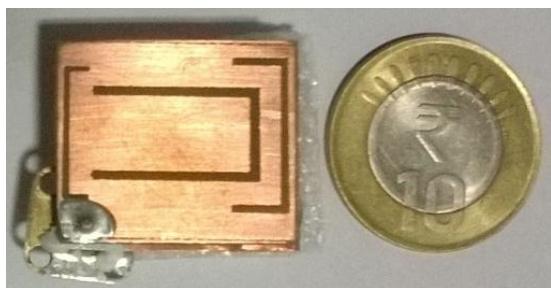

(a) Top view

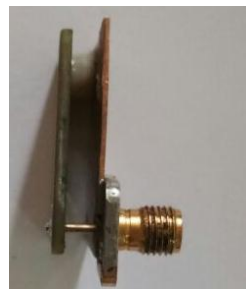

(b) Side view
Figure 6 Fabricated prototype of the suggested antenna

The design approach is observed and simulated at each step, it is noticed that the patch exhibits a better impedance matching with more number of slots digged on it and this variation with the number of slots is depicted in Figure 5. Also, this proposed structure exhibits a good gain response at the resonance frequencies as shown in Figure 7. A comparative study has been carried out using the different antenna configurations as shown in Figure 2. The gain response of antenna 1 is around $5 \mathrm{dBi}$, which is plotted in dotted line. In the second iteration, by using antenna 2 configuration the gain response is enhanced up to $6.5 \mathrm{dBi}$ which is plotted on dash line. Further the gain response is improved up to $7.28 \mathrm{dBi}$ using antenna 3 configuration which is shown in solid line as plotted in Figure 7.

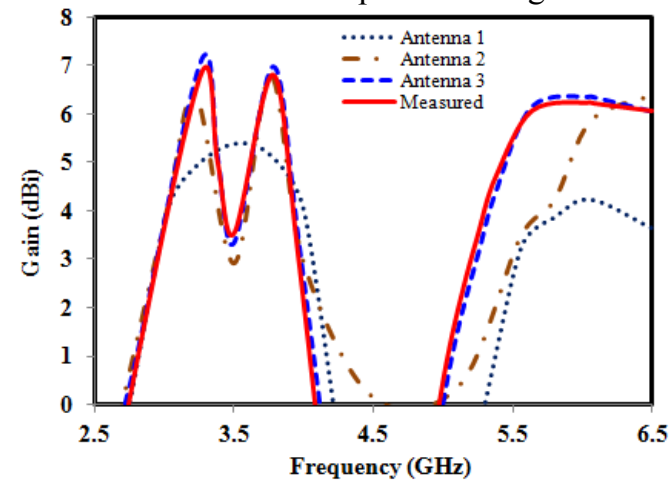

Figure 7 Gain response of the proposed antenna.
The iterative optimization of the antenna geometry using half U-slots yield better gain response $\quad(7.28 \mathrm{dBi}$ at 3.3 $\mathrm{GHz}, 6.95 \mathrm{dBi}$ at $3.78 \mathrm{GHz}$ and $4.6 \mathrm{dBi}$ at $5.3 \mathrm{GHz}$ ) than the previous two configurations.

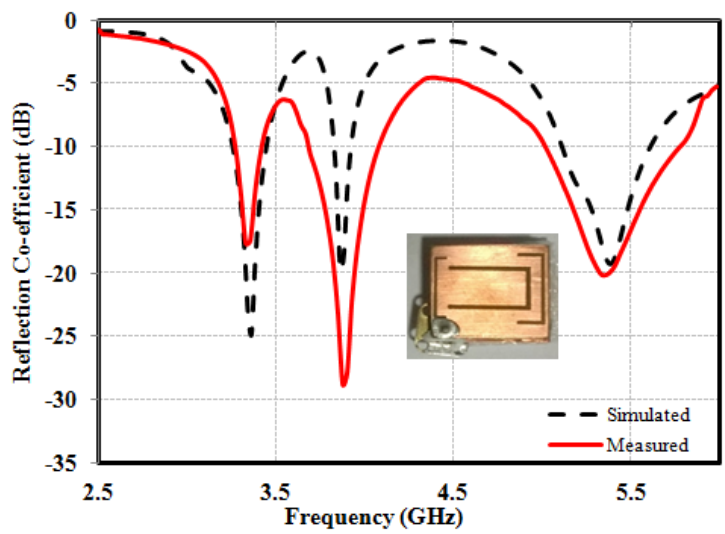

Figure 8 Measured and Simulated Return loss characteristics of the suggested antenna

The fabricated antenna is connected to a well calibrated VNA (Vector Network Analyzer) to obtain the resonance characteristics of the proposed antenna. It can be observed that measured resonance characteristics agree well with the simulated characteristics, all the three resonances perfectly coincide at the desired resonant frequency. Good agreement of the simulated and measured results is realized as the fabrication of this structure followed the proper photolithographic process. The measured and simulated return loss characteristics of the proposed antenna for WLAN / WI-MAX communication system is plotted in figure 8. Although the measured result plot shows a minor variation with the simulated result, this variation is negligible. However, both the results show a good return loss at each resonant frequency well below $-10 \mathrm{~dB}$ reference.

Table 5 Results obtained from proposed geometry

\begin{tabular}{cclll} 
Fr & \multicolumn{2}{c}{ Return Loss } & \multicolumn{2}{c}{ Gain } \\
$(\mathbf{G H z})$ & Simulated & Measured & Simulated & Measured \\
\hline 3.3 & $20.2 \mathrm{~dB}$ & $17.65 \mathrm{~dB}$ & $7.28 \mathrm{dBi}$ & $7.18 \mathrm{dBi}$ \\
3.7 & $17.9 \mathrm{~dB}$ & $28.82 \mathrm{~dB}$ & $6.95 \mathrm{dBi}$ & $6.05 \mathrm{dBi}$ \\
5.3 & $17.7 \mathrm{~dB}$ & $20.16 \mathrm{~dB}$ & $4.5 \mathrm{dBi}$ & $4.6 \mathrm{dBi}$ \\
\hline
\end{tabular}

The results obtained during simulation and measurement process is tabulated in Table 5. This comparative study confirms the measured return loss is better than the simulated return loss except at first resonance. In the same manner the measured gain response is better than the simulated results at third resonance.

The antenna is then placed in an anechoic chamber for the measurement of radiation characteristics. The antenna is fixed on a rotating hand where periodical movement with different angles is carried out. Eventually, the antenna is rotated to different positions with a $5^{\circ}$ step angle to measure the E-plane and H-plane radiation power. The copolarization and cross-polarization plots in E-plane and $\mathrm{H}$ plane are plotted in Figure 9. 


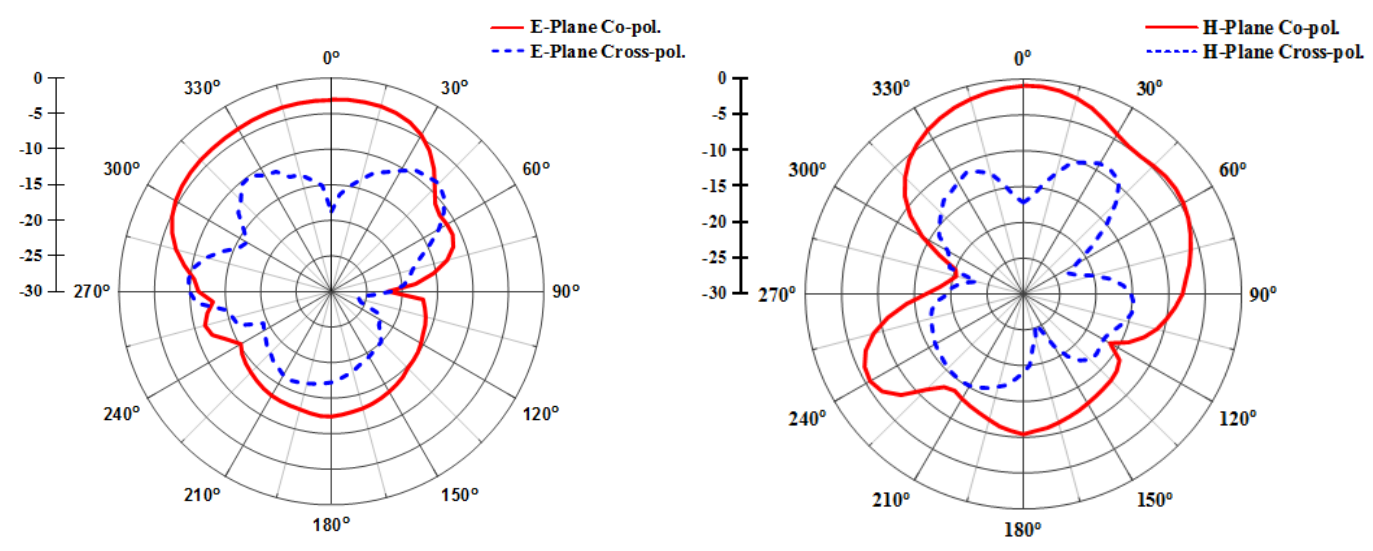

(a) $1^{\text {st }}$ Resonance $3.3 \mathrm{GHz}$
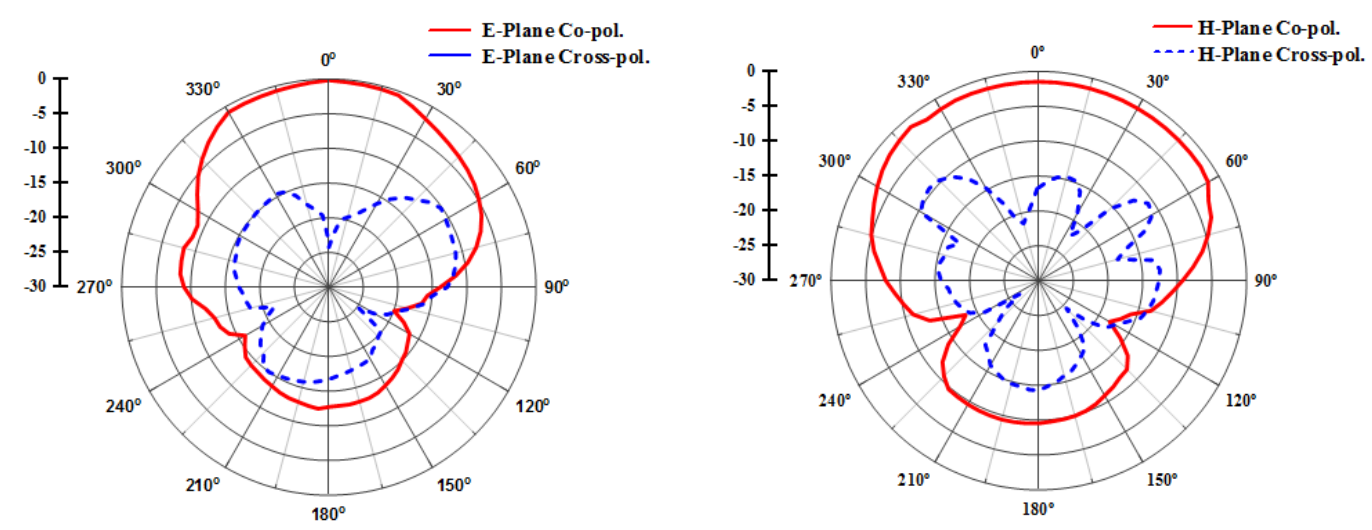

(b) $2^{\text {nd }}$ Resonance $3.7 \mathrm{GHz}$
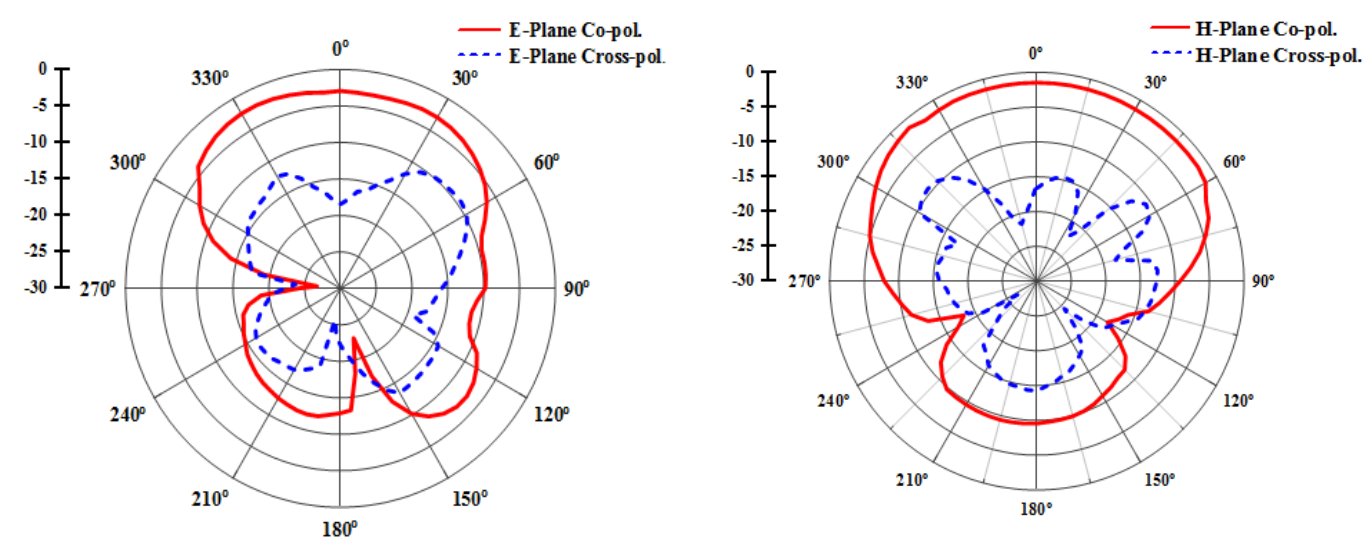

(c) $3^{\text {rd }}$ Resonance $5.3 \mathrm{GHz}$

Figure 9 Radiation pattern at each resonant frequency.

It can be observed that, at $3.3 \mathrm{GHz}$ the antenna radiates with HPBW of $55^{\circ}$ in the E- plane; at $3.7 \mathrm{GHz}$ it radiates with $80^{\circ}$ $\mathrm{HPBW}$ and at $5.3 \mathrm{GHz}$ it radiates with $75^{\circ} \mathrm{HPBW}$ towards E-plane. The cross-polarization characteristic of the said antenna is measured by rotating the antenna $90^{\circ}$ from its copolarization direction. As mentioned the linear polarized antenna is having good radiation in co-pol. direction and very poor radiation in cross-pol. Direction, so the measurement results hold a good agreement with the theoretical point of view. Back-end radiation exists in the proposed antenna as it is a suspended structure [20]. As desired, the co-polarization plot maintains a good $-3 \mathrm{~dB}$ half power beam width and also it is almost $0 \mathrm{~dB}$, whereas the cross-polarization is below the $-15 \mathrm{~dB}$ reference line.

The observed results during the simulation process match well with the results obtained during the measurement process. However, owning all these characteristics the 
antenna is proposed for WLAN/ Wi-MAX communication system.

\section{Conclusions}

In this paper, a suspended microstrip antenna with U- slots for triple band operation is designed. The resonant frequencies are $3.3 \mathrm{GHz}, 3.7 \mathrm{GHz}$ and $5.3 \mathrm{GHz}$, which can be used for applications for present-day wireless communication like WLAN and WiMAX. The probe feeding technique provides sufficient excitation to the radiator patch at the top layer. The impedance bandwidth as well as gain response is enhanced using the symmetrical Uslots. Maximum of $750 \mathrm{MHz}$ bandwidth is achieved with maximum of $7.18 \mathrm{dBi}$ boresight gain. It has been observed that the probe feed position affects the return loss and gain response. It should be noted that, with better optimization, tetra-band operation can be achieved.

\section{References}

[1] A. Balanis, Antenna theory analysis and design, Third edition, a john wiley \& sons, inc publication.

[2] G.G. Sanford, Multiple resonance radio frequency microstrip antenna structure, US Patent 4070676, Jan 1978.

[3] S. Long, M. Walton, A dual frequency stacked circular disc antenna, IEEE Transactions on Antennas and Propagation, Vol. AP-27,No. 2, pp.270-273, March 1979.

[4] C. M. Kaloi, Multi-band single-feed microstrip antenna system, US patent US4356492, Jan 1981.

[5] B. Wang, and Y. Lo, Microstrip antennas for dual-frequency operation, IEEE Transactions on Antennas and Propagation, Vol. 32, No. 9, pp. 938-943, Sep 1984.

[6] M. Nasher-Moghadasi, R.Sadeghzadeh, L. Asadpor and B.S. Virdee, A small dual-band CPW-fed monopole antenna for GSM and WLAN applications, IEEE Antennas Wireless Propagation Letters,Vol.12, pp. 508-511,Apr 2013.

[7] Xiao Lei Sun, Li Liu, S.W. Cheung and T. I. Yuk, Dual-band antenna with compact radiator for 2.4/5.2/5.8 GHz WLAN applications, IEEE transactions on Antennas and Propagation, VOL. 60, No. 12, December 2012.

[8] A. Khaleghi, Dual-band Meander line antenna for wireless LAN communication, IEEE Transactions on Antenna Propagation, Vol.55, No. 3, pp. 1004-1009, Mar 2007.

[9] Y.S. Wang, M.C. Lee and S.J. Chung, Two PIFA-related miniaturized dual-band antennas, IEEE Transaction Antennas and Propagation, Vol. 55, No.3, pp.505-511, March 2007.

[10] T. Huynh and K.-F. Lee, Single-layer single-patch wideband microstrip antenna, Electronics Letters , Vol. 31 No. 16, August 1995.

[11] H. wang, X. Huang, and D. Fang, A single layer wideband Uslot microstrip patch antenna array, IEEE Antennas and Wireless Propagation Letters, Vol. 7, pp. 9-12, 2008.

[12] B. Ooi, A double-II stub proximity feed U-slot patch antenna, IEEE Transactions on Antennas and Propagation, vol. 52, no. 9, pp. 2491-2496, September 2004.

[13] S, Liu, W. Wu, and D. Fang, Single-feed dual-layer dual-band E-shaped and U-slot patch antenna for wireless communication application, IEEE Antennas and Wireless Propagation Letters, vol. 15, pp. 468-471, February 2016.
[14] Se-Keun Oh, Hyung- Sik Yoon, Seong-Ook Park, A PIFA type varactor -tunable slim antenna with a PIL patch feed for multiband applications. IEEE Antennas and Wireless Propagation Letters, Vol.6. 2007.

[15] K. Jhamb, L. Li, K. Rambabu, Novel-integrated patch antennas with multiband characteristics. IET Microwave Antennas and Propagation, Vol.12, No.5, 1393-1398, 2011.

[16] C.Y.D. Sim, F.R.Cai, Y.P. Hsieh, Multiband slot ring antenna with single and dual-capacitive coupled patch for wireless local area network/worldwide interoperability for microwave access operation. IET Microwave Antennas and Propagation, Vol.5, No.15,1830-1835,2011.

[17] Ming Tien Yu, Ming Lian Chuang, Multibroadband slotted bow-tie monopole antenna.IEEE Antennas and Wireless Propagation Letters, Vol. 14. 2015.

[18] C.J. Wang, S.W. Chang, Studies on dual band multislot antennas. Progress In Electromagnetics Research, PIER 83, 293-306, 2008.

[19] Y. F. Cao; S. W. Cheung; T. I. Yuk, A multiband slot antenna for GPS/WiMAX/WLAN systems. IEEE Transactions on Antennas and Propagation, Vol.63,No.3.,2015.

[20] S. Mohapatra, D.Barad and S. Behera, Analysis of multiresonance characterestics in suspended ring antenna applicable for iot/wsn, Progress in Electromagnetic Research M, Vol. 57,11-24, 2017.

[21] R. Bhalla and L.Shafai, Resonance behavior of single U-slot Microstrip patch antenna, Microwave and Optical Technology Letter, Vol.32, No. 5,pp:333-335, March 2002..

[22] J.D. Kraus, Antennas and Wave Propagation, Fourth edition, Tata McGraw Hills Publication. 